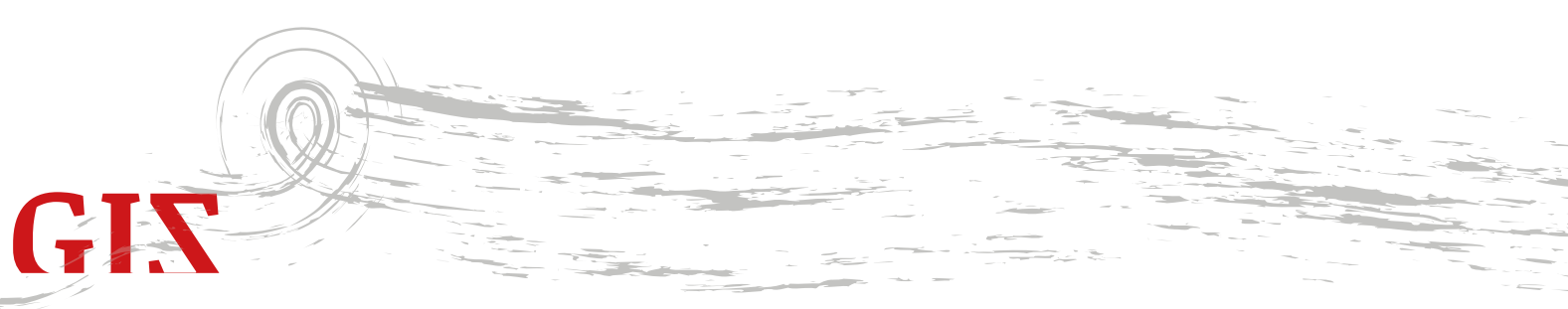

São Paulo, Brasil CARLOS FADON VICENTE

\title{
VORTEX: UMA CRÔNICA VISUAL
}

Formulado como um ensaio fotográfico, Vortex (2013-presente) tem seu eixo poético na cena/realidade imediata, operando o jogo e a mescla entre algo que se pressente e aquilo que se encontra. Seu substrato temático é o desarranjo sociocultural exposto no conflito, no desgaste e no desmanche - às vezes, na elevação presentes na micropaisagem urbana, vista como janela, espelho e anteparo. São fantasmáticos ecos e sinais de um turbilhão em processo, daí seu título.

A obra assinala o aprofundamento de uma vertente conceitual da representação fotográfica centrada na polaridade certeza/incerteza. Tem-se, em essência, a combinação entre pressentido e encontrado, afastando-se da dicotomia quase didática entre as posturas de construtor e de caçador, comumente associada à fotografia de rua.

Vortex tem sua seara e sua motivação na vivência urbana, assentando-se em ligações intra e interimagem. Trilha uma estética minimalista, permeando a composição de formas e cores. Avizinha-se do ensaio Diários (1990-presente) na medida que se desenvolve à maneira de uma crônica visual, cujo enredo mescla determinação e indeterminação. 
Vortex: uma crônica visual

Carlos Fadon Vicente

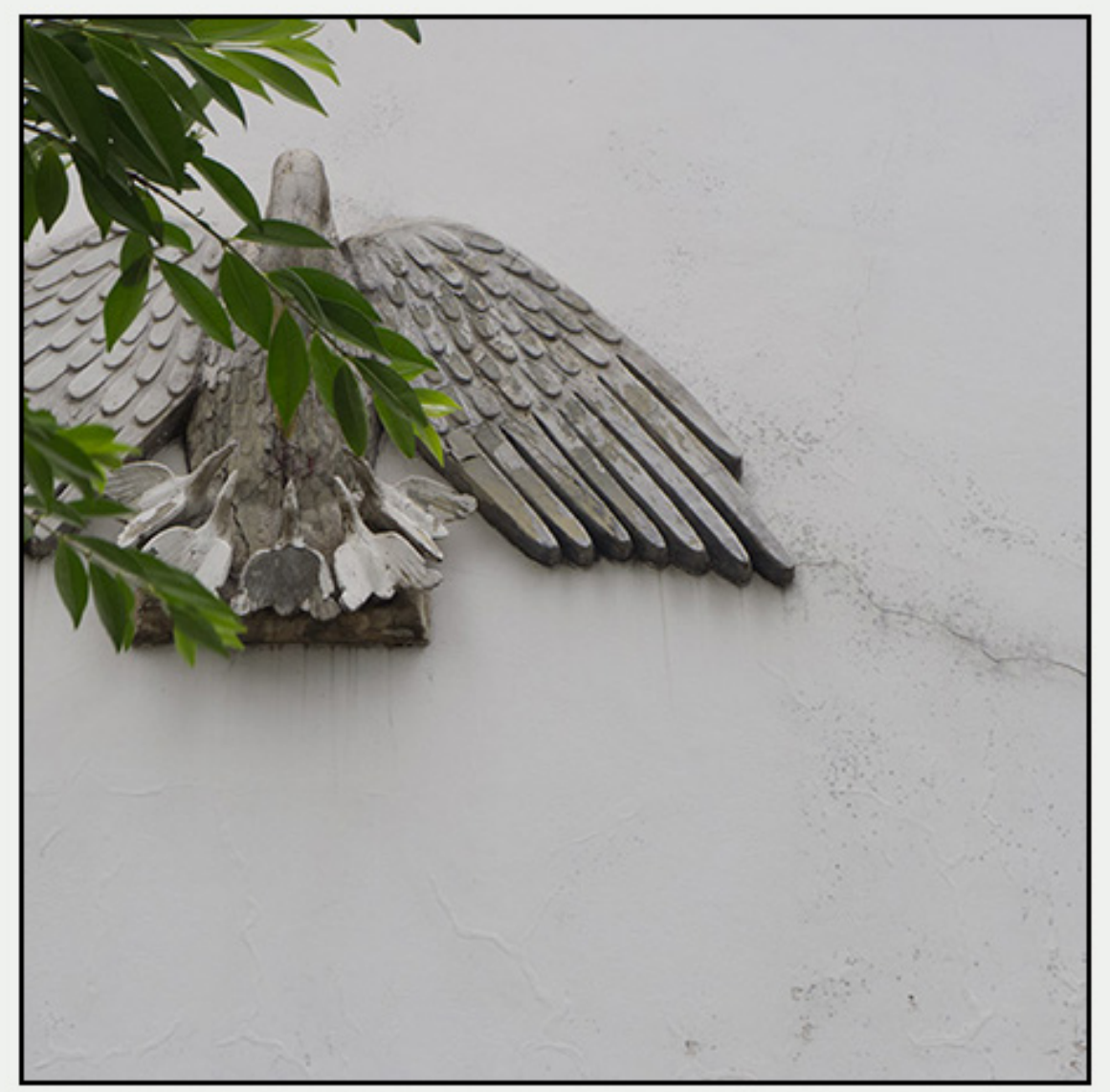



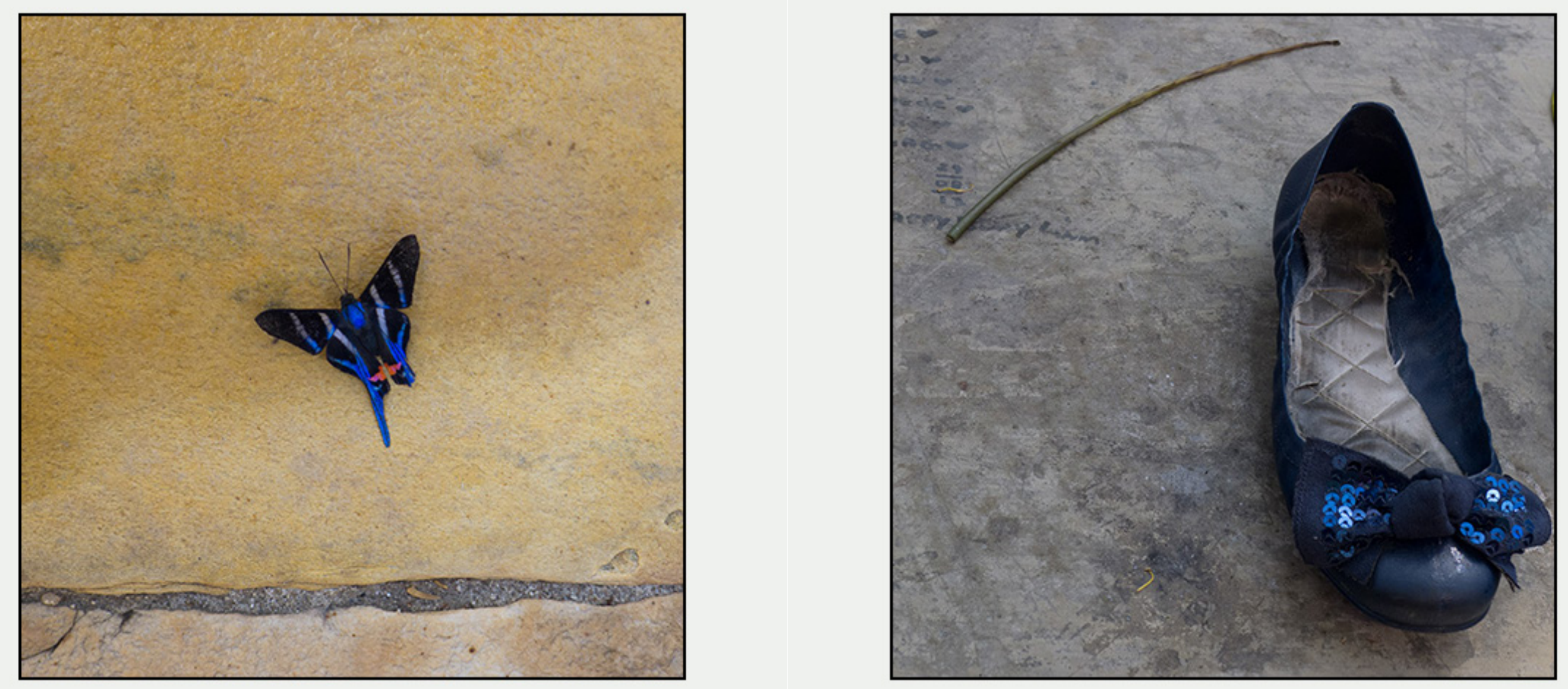

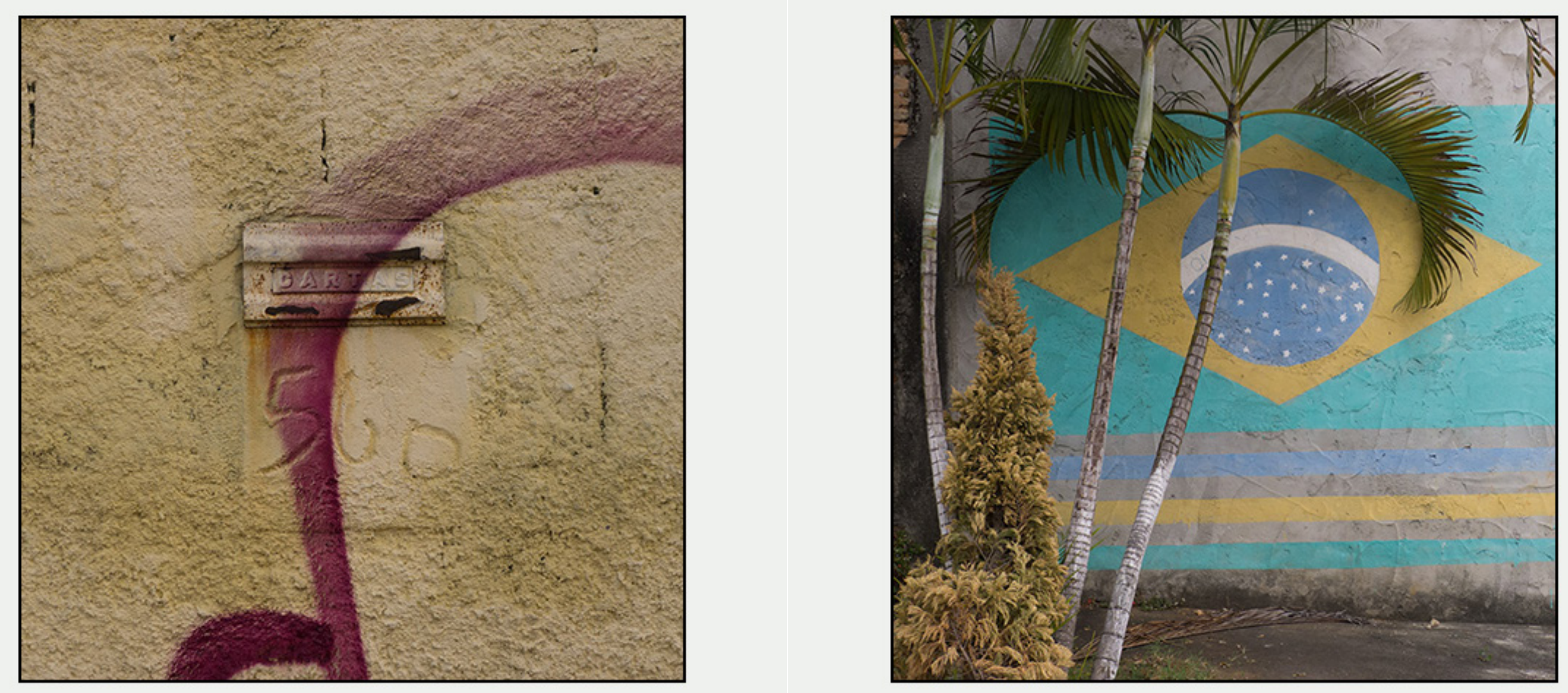


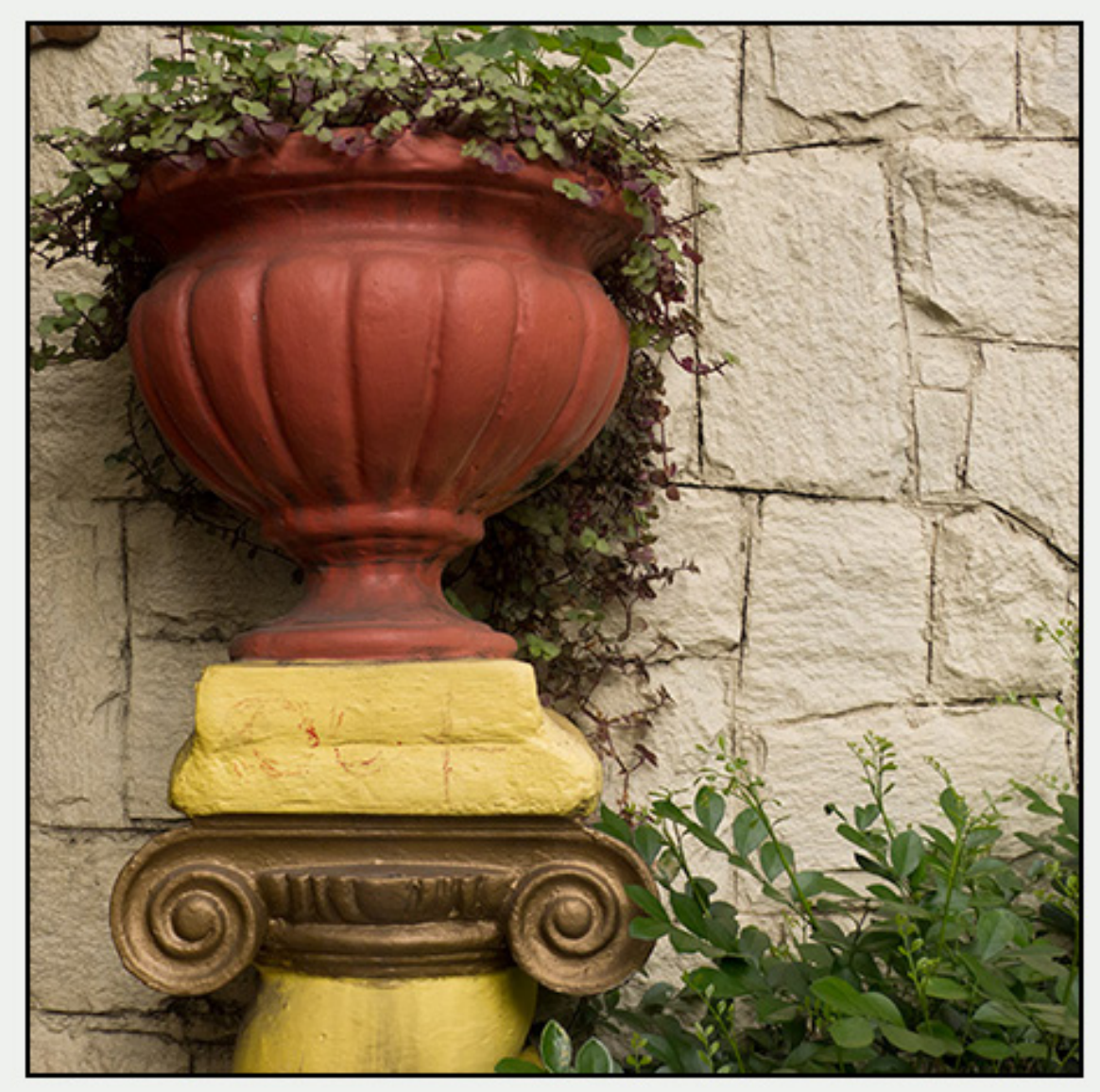



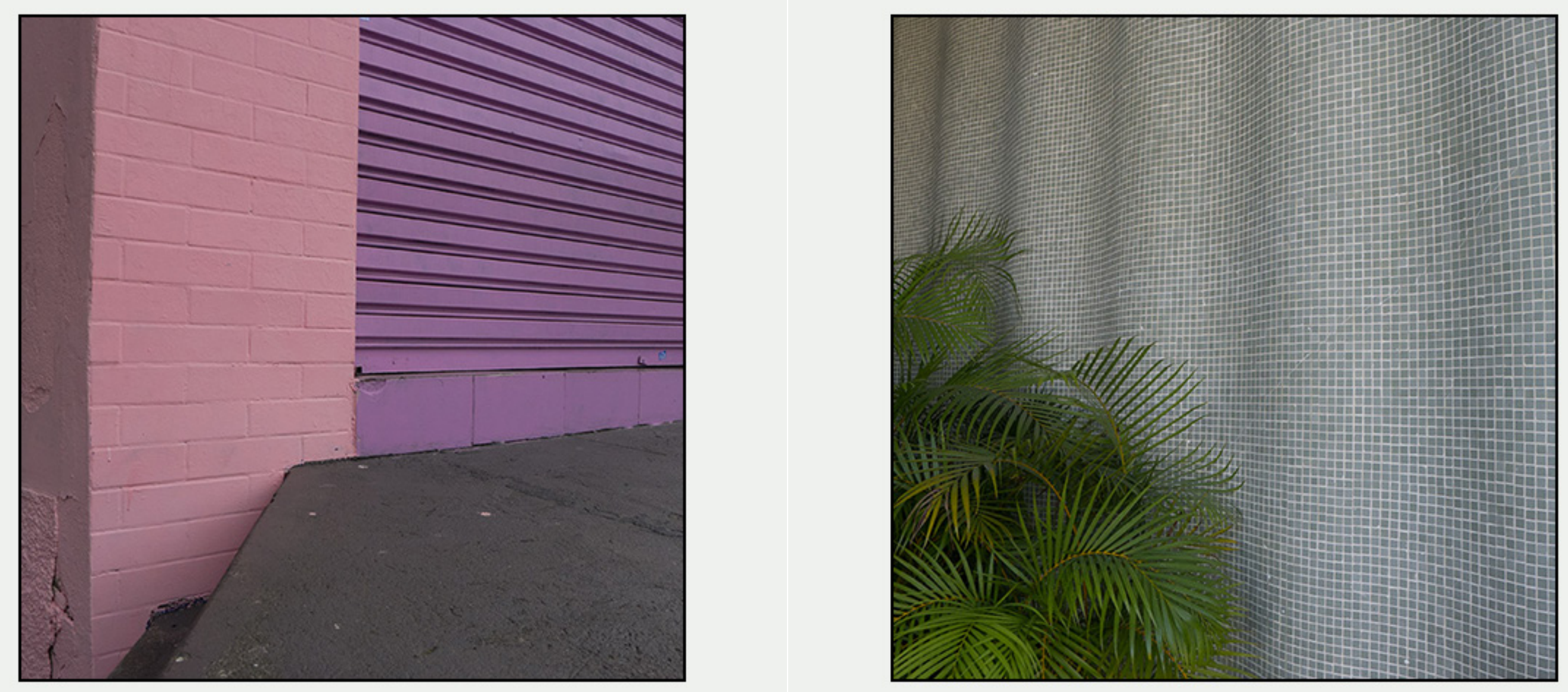

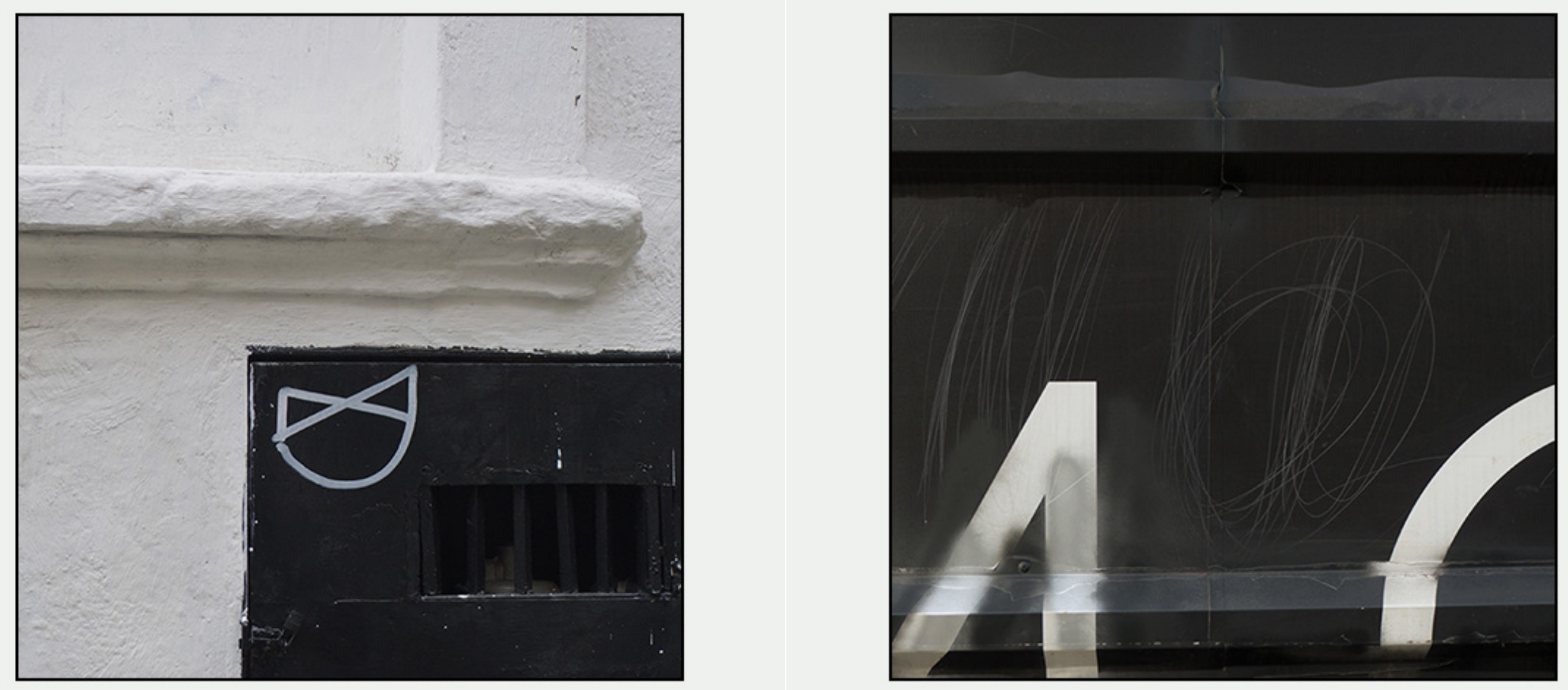

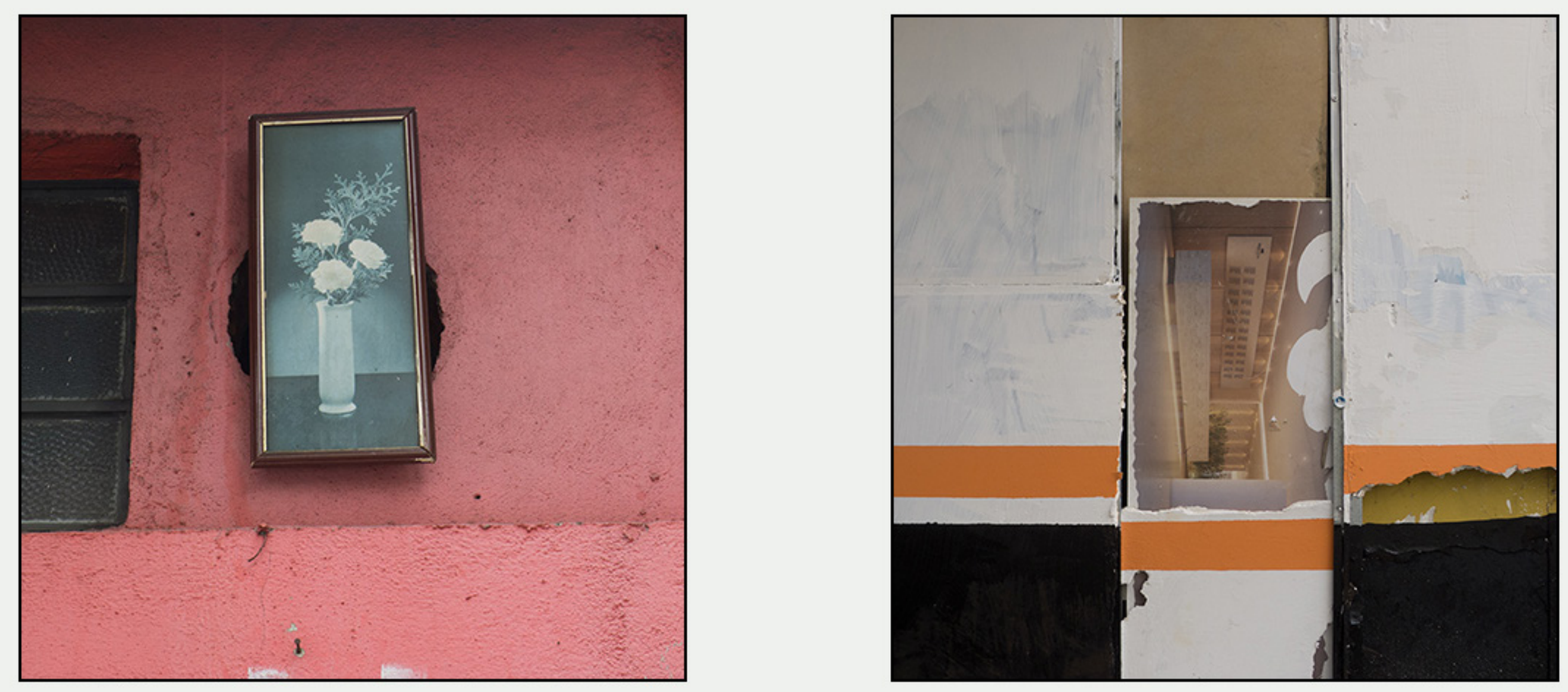


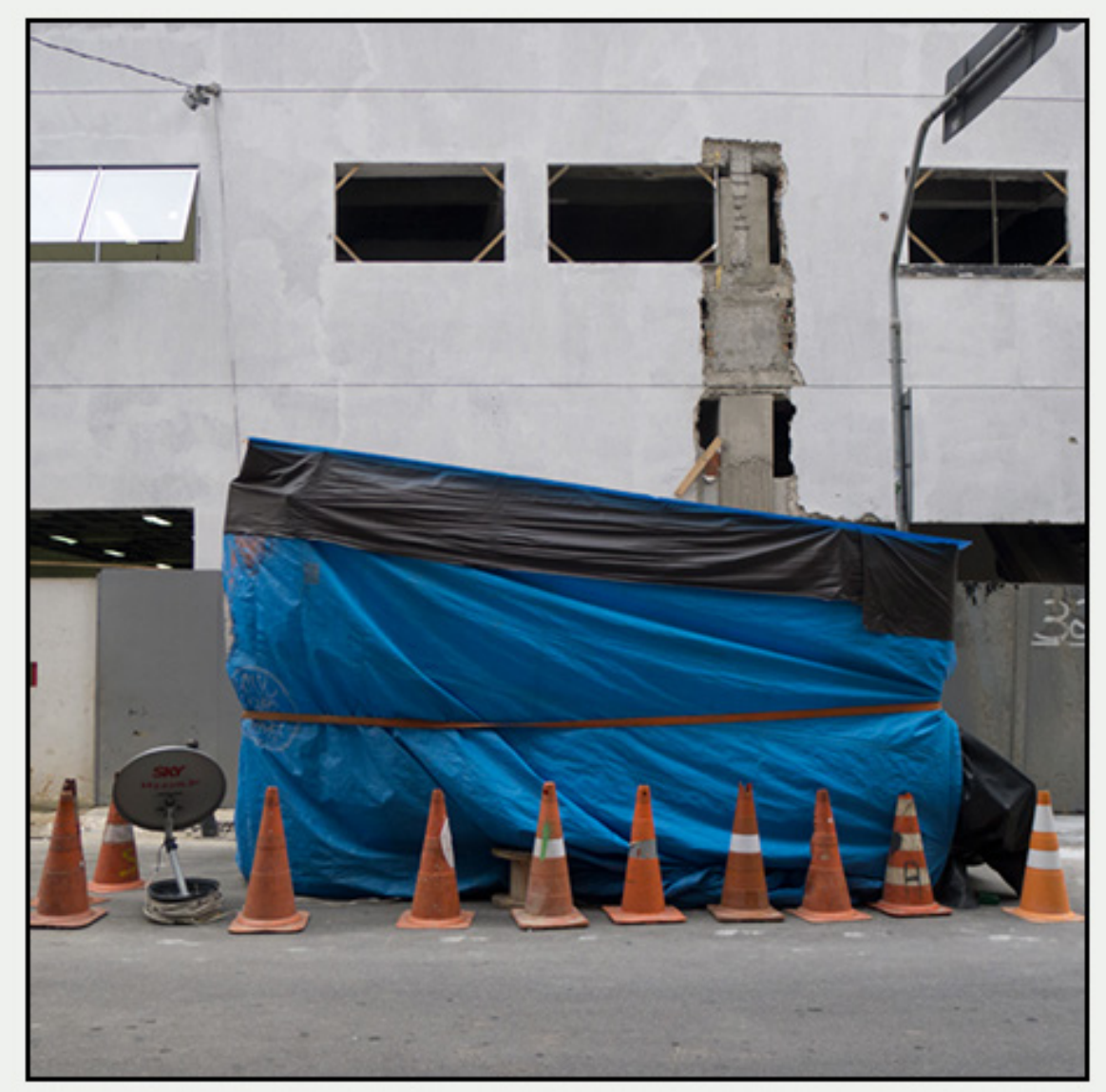




\section{CARLOS FADON VICENTE}

Fotografia (1975) e media art (1985) são vertentes centrais e interdependentes de sua atividade artística. Sua produção tem sido apresentada em exposições individuais, eventos e mostras coletivas, em coleções públicas e privadas, em publicações com artigos, entrevistas e portfólios, além de palestras e cursos, no Brasil e no exterior.

recebido Nascido em São Paulo, 1945, sua formação compreende doutorado em ar10.01.2018 tes visuais pela Universidade de Évora, mestrado em arte e tecnologia pela aprovado School of the Art Institute of Chicago e graduação pela Escola Politécnica e 18.01.2018 pela Escola de Comunicações e Artes da Universidade de São Paulo. 